\title{
USING THE ACTIVE FAULTS OF EURASIA DATABASE FOR SOLVING TECTONIC PROBLEMS
}

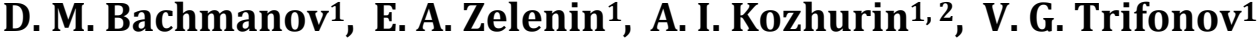 \\ ${ }^{1}$ Geological Institute of RAS, Moscow, Russia \\ 2 Institute of Volcanology and Seismology, Far East Branch of RAS, Petropavlovsk-Kamchatsky, Russia
}

\begin{abstract}
The article describes principles, methods and tasks of tectonic studies using computer processing of the Active Faults of Eurasia Database. This new database contains more than 30000 objects that are geographically linked, equipped with attributes of the kinematic type, estimated movement rates and activity confidence ranks. As an example, we consider processing of the data on several tectonic regions of the Alpine-Himalayan mobile belt and construction of rose-diagrams of faults for a comparative analysis of their Late Cenozoic kinematics. The processed data set also covered the Caucasus-Anatolian region and the entire central part of the mobile belt, and fields of shortening/lengthening and shearing were mapped to assess the patterns of these processes in different areas and to determine the characteristics of the tectonic flow of the upper crust material. Prospects are discussed for the database processing with the use of all the available attributive information for structural-kinematic and geodynamic analysis, including processing of the database in combination with independent remote and geophysical data.
\end{abstract}

Key words: active fault; database; computer processing

For citation: Bachmanov D.M., Zelenin E.A., Kozhurin A.I., Trifonov V.G., 2019. Using the Active Faults of Eurasia Database for solving tectonic problems. Geodynamics \& Tectonophysics 10 (4), 971-993. doi:10.5800/GT-2019-10-4-0453.

Funding: This study was financed by the Russian Science Foundation (Project No. 17-17-01073). The source materials were partially collected in the studies under the budget topic of the Geological Institute RAS (No. AAAA-A17-117030610107-3). 


\title{
ИСПОЛЬЗОВАНИЕ БАЗЫ ДАННЫХ АКТИВНЫХ РАЗЛОМОВ ЕВРАЗИИ ПРИ РЕШЕНИИ ТЕКТОНИЧЕСКИХ ЗАДАЧ
}

\author{
Д. М. Бачманов ${ }^{1}$, Е. А. Зеленин ${ }^{1}$, А. И. Кожурин ${ }^{1,2}$, В. Г. Трифонов ${ }^{1}$ \\ 1 Геологический институт РАН, Москва, Россия \\ ${ }^{2}$ Институт вулканологии и сейсмологии ДВО РАН, Петропавловск-Камчатский, Россия
}

\begin{abstract}
Аннотация: Описываются принципы, методики и задачи тектонических исследований с применением компьютерной обработки новой базы данных активных разломов Евразии, содержащей более 30000 географически привязанных объектов, снабженных атрибутами кинематического типа, оценками скоростей движения и достоверности активности. В качестве примеров рассмотрена обработка отдельных тектонических областей Альпийско-Гималайского подвижного пояса с построением роза-диаграмм разломов для сравнительного анализа их позднекайнозойской кинематики. Также проведена обработка Кавказско-Анатолийского региона и всей центральной части подвижного пояса с построением карт полей деформаций сокращения - удлинения и сдвига для оценки их распределения в разных областях и выяснения характеристик тектонического течения верхнекоровых масс. Обсуждаются перспективы обработки базы данных с использованием всего комплекса содержащейся в ней атрибутивной информации для структурно-кинематического и геодинамического анализа, в том числе обработки базы данных совместно с независимыми дистанционными и геофизическими материалами.
\end{abstract}

Ключевые слова: активный разлом; база данных; компьютерная обработка

\section{1. ВВЕДЕНИЕ}

Компьютерная обработка геологической информации, представленной в форме баз данных, является важным методом современных научных исследований. Она позволяет осуществлять автоматизированный анализ множества геологических объектов на обширной территории, выявлять их дополнительные характеристики. Базы данных по активной тектонике ценны тем, что представляют однородный по охватываемому геологическому времени материал, что позволяет выполнять сравнительный анализ даже удаленных друг от друга территорий.

Примером может служить электронная база данных активных разломов Евразии, созданная в 1996 году под руководством В.Г. Трифонова в рамках Международного проекта II-2 «Карта крупных активных разломов мира» Международной программы «Литосфера». База содержала информацию о более чем 10000 разломов значительной части Евразийского континента и прилегающих акваторий. На ее основе была построена Карта активных разломов Евразии масштаба 1:5000000 [Trifonov, 1997, 2004]. Компьютерная обработка базы данных позволила создать карты, отражающие распределение тектонических напряжений и деформаций Альпийско-Гималайского пояса [Trifonov et al., 2002]. Созданные на ее основе сейсмотектониче- ские материалы были использованы при создании Комплекта карт общего сейсмического районирования территории Российской Федерации ОСР-97 [Ulomov, Shumilina, 1999].

Другими примерами баз данных такого рода являются Новая электронная карта активных разломов юга Восточной Сибири [Lunina et al., 2010] и Цифровая карта разломов для плиоцен-четвертичного этапа развития земной коры юга Восточной Сибири и сопредельной территории Северной Монголии [Lunina, 2016]. Карты включают большое количество объектов с детальной и хорошо систематизированной информацией об активной разломной тектонике. Их компьютерная обработка позволила получить многочисленные картографические и другие материалы, отражающие новейшую и современную геодинамику региона.

Как правило, интеграция сведений об активных разломах ограничивается разработкой формальной структуры и наполнением баз данных (например [Basili et al., 2008; Styron et al., 2010]). Дальнейшая их обработка проводится преимущественно для решения задач оценки сейсмической опасности (например [Woessner et al., 2015]). Возможности автоматизированной обработки баз данных об активных разломах для решения фундаментальных геодинамических задач до настоящего времени оставались за пределами внимания исследователей, что, возможно, связано с относительно ком- 
пактным охватом этих исследований, доступным для экспертной оценки без привлечения программных средств.

Разработка новой базы данных активных разломов Евразии (далее - БД) была проведена в 2017 году. В настоящее время БД продолжает уточняться и дополняться с целью интеграции в едином формате всех накопленных разнородных сведений, касающихся активной разломной тектоники Евразии. Она вмещает более 30000 географически привязанных объектов - разломов, выделенных как активные в конце плейстоцена и голоцене с той или иной степенью достоверности, классифицированных по скорости и кинематике (рис. 1). Детальность привязки линий разломов к рельефу земной поверхности позволяет демонстрировать их в виде карты масштаба 1:1000000. Каждый объект БД (активный разлом) имеет девять атрибутов, три из которых посредством индексов отражают кинематический тип разломов (сорок два сочетания главной и второстепенной компонент смещения), ранг скорости позднечетвертичных движений (три градации) и степень достоверности выделения структуры как активной (четыре градации), что позволяет сопоставлять объекты между собой и с другими цифровыми данными с помощью любой ГИСпрограммы. Таким образом, БД не только содержит сведения о конкретных разломах, но и дает возможность решать общие проблемы современной геодинамики и плиоцен-четвертичной истории тектонического развития разных регионов Евразии. В полном объеме содержание БД представлено на сайте Геологического института РАН [Active Faults Database, 2019] в виде электронной карты разломов, наложенных на топографическую основу, с возможностью показа всех их атрибутов.

Принципы составления и формат содержания базы данных активных разломов Евразии подробно изложены в статье [Bachmanov et al., 2017]. Цель предлагаемой статьи - на примере отдельных конкретных вариантов компьютерной обработки БД показать значение, возможности и перспективы программного использования больших массивов цифровых данных по активным разломам для решения тектонических и геодинамических задач. Рассматриваются принципы и способы компьютерной обработки данных и формы представления получаемых результатов, обсуждаются вопросы выбора районов и участков изучаемой территории, оптимальных для обработки с целью сравнительной интерпретации, предлагаются варианты формализованной классификации их тектонических характеристик на основе обработки БД. Предлагаются способы графического представления результатов обработки, наилучшим образом отвечающие выбранному алгоритму и наиболее точно выража- ющие геологический смысл изучаемых явлений. Приводятся отдельные примеры результатов обработки.

\section{2. ОБЩИЕ ПРИНЦИПЫ ОБРАБОТКИ БД}

Первая и очевидная цель обработки БД - представление активных разломов и их некоторых поддающихся визуализации параметров на карте. Простейший случай - визуализация кинематики разломов с помощью цвета или их достоверности с помощью традиционного для легенд геологических и тектонических карт графического приема (сплошные и пунктирные линии). Очевидно, что задача усложняется, если предметом изучения и визуализации выступает сочетание свойств (атрибутов). В этом случае требуется путем их совместной обработки рассчитать производную от них новую величину, характеризующую исследуемое сочетание исходных свойств. Такую величину мы называем «расчетным параметром». Например, чтобы отобразить соотношение сдвиговой и вертикальной компонент смещения по разлому, необходимо путем обработки его кинематических атрибутов вычислить вектор скорости движения, а затем осуществить его разложение на горизонтальную и вертикальную составляющие. В данном случае расчетным параметром являются величины частных компонент скорости. Можно рассчитать параметр из атрибутов разного типа, например атрибута кинематики и атрибута достоверности. Итогом может быть заключение, что сдвиги выделяются с большей уверенностью, чем надвиги. Такой вывод, если он сделан, по сути, представляет результат интерпретации расчетного параметра - характеристику некоторой территории (участка). Условимся называть результат интерпретации расчетного параметра «целевой характеристикой».

Обработка БД может дать также результаты, которые нельзя получить при визуальном анализе карты разломов. Так, если общий характер частоты, скорости, ориентировки разломов демонстрируется их изображением на карте, то вычисление точных величин названных параметров позволяет предметно сравнивать внешне похожие на карте области, выявлять их различия, незаметные на карте. Такие скрытые различия могут оказаться новой информацией, отправной для дальнейшего исследования.

Из сказанного выше следует, что тектонические исследования на основе компьютерной обработки БД предполагают алгоритм действий, включающий три этапа преобразования информации.

На первом этапе составления БД в результате экспертной оценки комплекса первичных матери- 


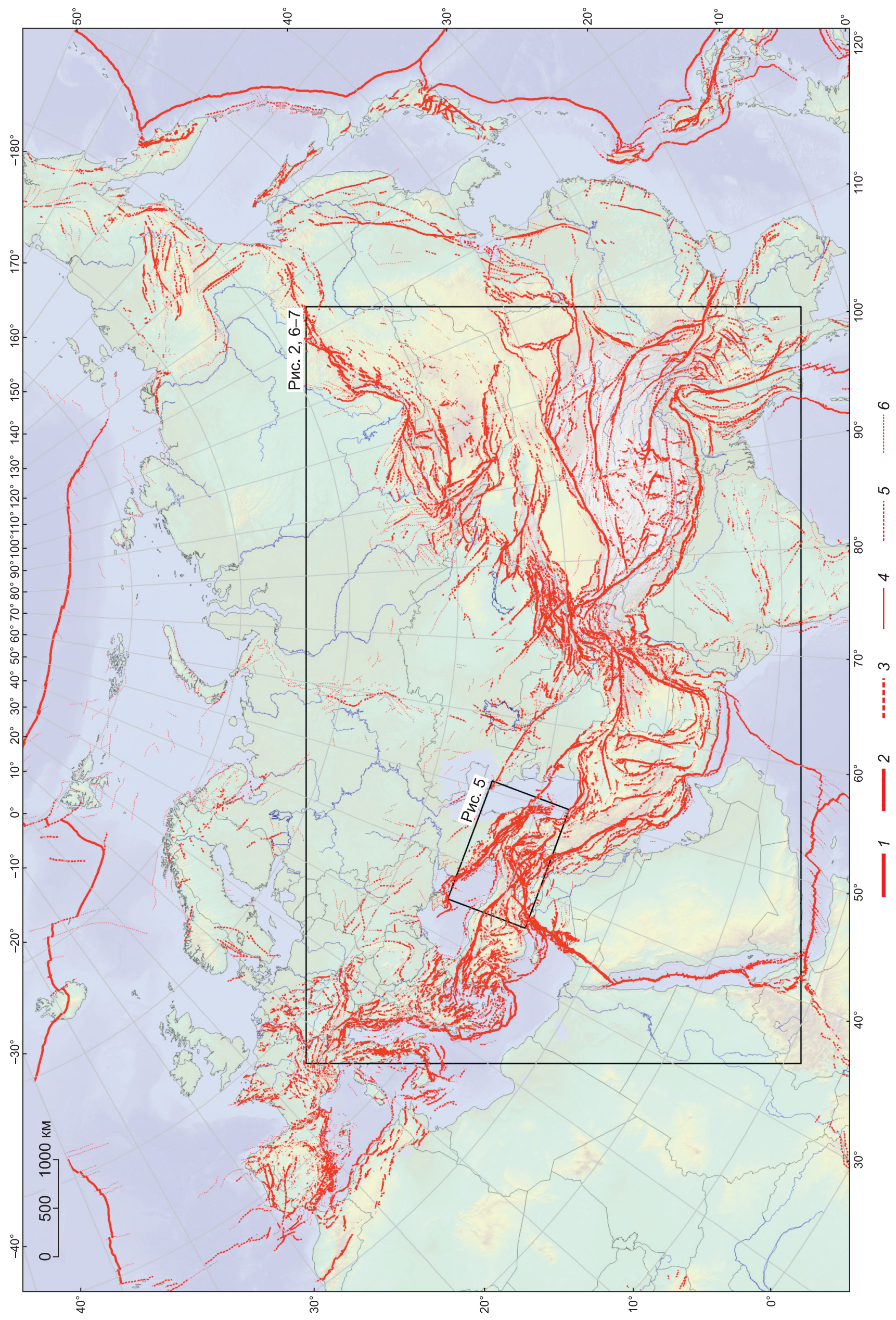


Рис. 1. Визуализация базы данных активных разломов Евразии: карта разломов.

1-6 - активные разломы со скоростями движений разного ранга и разной достоверностью активности: 1 - ранг 1 и достоверность А и В, 2 - ранг 2 и достоверность А и В, 3 - ранг 2 и достоверность С, 4 - ранг 3 и достоверность А и В, 5 - ранг 3 и достоверность C, 6 - ранг 3 и достоверность D.

Fig. 1. Visualization of the Active Faults of Eurasia Database: fault map.

1-6 - active faults and velocities of movements of different ranks and different activity confidence categories: 1 - rank 1 and confidence category A and B, 2 - rank 2 and confidence category A and B, 3 - rank 2 and confidence category C, 4 - rank 3 and confidence category A and B, 5 - rank 3 and confidence category C, 6-rank 3 and confidence category D.

алов из публикаций-источников или личных наблюдений составителей всем объектам присваиваются атрибуты, отражающие реальные природные структурно-кинематические и другие свойства отдельных разломов. Эти атрибуты представляют исходные данные для дальнейшей компьютерной обработки.

На втором этапе, в результате обработки атрибутов для всех объектов, входящих в определенные выбранные участки территории, вычисляются расчетные параметры, которые отражают некоторые формальные показатели (уже не отдельных разломов, а целых участков, в пределах которых они расположены) и отображаются на иллюстративных материалах в той или иной форме. Конкретный расчетный параметр участка может представлять собой одну цифру, а может включать набор значений, комплексно отражающий свойства выбранного участка посредством сложного символа, графика или диаграммы. Некоторые расчетные параметры, получаемые при обработке атрибутов объектов БД, приведены в таблице 1. Этот перечень не претендует на завершенность и может расширяться исследователем.

Третий этап заключается в геологической интерпретации расчетных параметров и получении целевых характеристик, отражающих уже не формальные параметры, а конечную цель исследования - реальные тектонические и геодинамические свойства участков, групп участков или всей изучаемой территории. Некоторые целевые характеристики, получаемые при интерпретации расчетных параметров, приведены в таблице 2. Полезен совместный анализ взаимосвязанных характеристик, например поиск соотношений между тектонической активностью и концентрацией деформаций или между ориентацией напряжений, кинематической ситуацией и структурной однородностью. Каждую характеристику можно оценить, используя разные расчетные параметры, а сходные по смыслу параметры можно рассчитать на основе разных атрибутов БД.

Возможна также обработка БД только на основе наличия активных разломов на той или иной тер- ритории и их пространственного положения. Обработка этой информации позволяет получить такие параметры участков, как плотность распределения разломов на единицу площади карты, их преобладающая ориентировка и разброс ориентировок, средний модуль изломов тектонических нарушений (показатель их извилистости), среднее значение изломов (показатель дугообразности) и т.п.

К общей схеме «атрибут - расчетный параметр целевая характеристика» добавим пояснения по трем аспектам.

1. В отличие от визуального анализа карты разломов, при котором учет их формы, протяженности и соотношений со смежными структурами обусловлен экспертным опытом исследователя, при автоматизированной обработке БД требуется выбрать алгоритм распределения значений атрибутов объектов по площади включающего их участка. Пространственно (географически) привязанными являются атрибуты и их производные - расчетные параметры. Их распределение по площади определяется расположением активных разломов. Отнесение значения атрибута или расчетного параметра только к одной референтной точке на разломе (например, центральной) непродуктивно - сеть точек со значениями расчетного параметра оказывается очень редкой, при этом не учитываются различия в протяженности и форме объектов, поэтому результаты обработки могут искаженно отражать структурные соотношения разломов. Избежать этого позволяет разделение разломов на сегменты равной длины и отнесение свойств (значений атрибутов) разломов к центральной точке каждого его сегмента. Единая для всех разломов длина сегмента выбирается в зависимости от требуемой детальности исследования и будет определять плотность точек, равномерно распределенных вдоль разломов и представляющих их свойства на всем протяжении (с учетом возможных изгибов), а поэтому адекватно выражающих сочленения смежных структур.

2. Обработка БД возможна двумя способами. Первый - это раздельная обработка выделенных по определенным критериям обособленных meстовых участков для их сравнения между собой в 


\section{T а б л и ц а 1. Возможные расчетные параметры тестовых участков, получаемые при обработке атрибутов разломов - объектов БД}

$\mathrm{T}$ a b l e 1. Possible parameters of test sites calculated by processing fault attributes (database objects)

\begin{tabular}{lll}
\hline Атрибут & Расчетный параметр & Пояснения \\
\hline $\begin{array}{l}\text { Компоненты } \\
\text { смещения }\end{array}$ & $\begin{array}{l}\text { Преобладающая } \\
\text { кинематика }\end{array}$ & $\begin{array}{l}\text { Показывает, какие типы разломов характерны для региона, а также степень } \\
\text { преобладания главного типа над второстепенным. Наиболее полно } \\
\text { иллюстрируется графически в виде роза-диаграмм }\end{array}$
\end{tabular}

Дисперсия кинематики

Соотношение компонент

Совместимость кинематики

Ориентация сместителей

Ориентация сжатия (сокращения)

Горизонтальная скорость

Вертикальная скорость

Средняя и

Степень достоверности CONF
Показывает разнообразие кинематики разломов, отражает изменчивость структурно-кинематической обстановки по площади. Параметр зависит от площади тестового участка: с увеличением площади степень дисперсии, очевидно, будет возрастать

Отражает соотношение между горизонтальной и вертикальной составляющими движений. Явное преобладание одной компоненты может указывать на определенные структурно-кинематические и геотектонические обстановки (фронтальные зоны коллизии, трансформные границы, зоны рифтогенеза, области блоковых движений). Нейтральные значения параметра при высоком уровне общей активности могут быть признаками переходных зон между разнородными областями

Определяет, насколько соотношения смежных объектов соответствуют тектонофизическим правилам. Отражает степень структурно-кинематической целостности системы нарушений, закономерности пространственных соотношений объектов. От параметра «соотношение компонент» отличается акцентом на соответствие тому, «как должно быть». Косвенно помогает оценить надежность исходных данных

Рассчитывается по главной компоненте движения и индексу поднятого крыла. Характеризует структурно-кинематическую обстановку и, с долей условности, отражает вергентность активных структур, направление движения коровых масс, тектонического течения

Характеризует поле напряжений в пределах участка и, с долей условности, описывает направление горизонтальной составляющей сокращения при допущении, что сокращение ориентировано параллельно сбросу, поперечно надвигу и косо (в соответствующую сторону) к сдвигу. После осреднения для всех объектов участка получается азимутальная угловая величина, которая интерпретируется как горизонтальная проекция оси сжатия в пределах участка. Дисперсия значений параметра (разброс ориентировок осей сжатия) отражает неоднородность структурно-кинематической обстановки и поля напряжений

Сумма значений атрибута всех объектов на участке отражает общую интенсивность и, отчасти, степень концентрации деформаций. Возможен расчет параметра средней скорости, т.е. суммарной скорости, нормированной на число объектов, которая лучше отражает степень концентрации деформаций (при этом важно обоснование размеров окна осреднения)

Отражает горизонтальную проекцию вектора скорости. По атрибутам кинематики для каждого объекта определяется пространственное положение вектора перемещения и выделяется его горизонтальная составляющая. Это позволяет выявлять области с преобладанием горизонтальных перемещений (сдвиговые и надвиговые парагенезисы)

Отражает вертикальную проекцию вектора скорости. Параметр позволяет выявлять области преобладания вертикальных движений (взбросовые и сбросо-раздвиговые парагенезисы) по их общей интенсивности либо степени концентрации движений

Характеризует общий уровень активности территории, позволяет проводить ее формализованное районирование. Косвенно отражает время наиболее интенсивных движений по активным разломам в течение позднекайнозойского этапа. Достоверность объекта может учитываться для придания удельного веса любому атрибуту, определяя его значимость относительно других объектов в усредняемой выборке 


\section{T а б л и ц а 2. Возможные целевые характеристики тестовых участков, получаемые при интерпретации расчетных параметров}

$\mathrm{T}$ a b l e 2. Possible target characteristics of test sites obtained by interpreting calculated parameters

\begin{tabular}{lll}
\hline Расчетные параметры & Целевая характеристика & Пояснения \\
\hline Общая скорость & Тектоническая активность & $\begin{array}{l}\text { Общий уровень активности структур, интенсивность } \\
\text { Средняя достоверность }\end{array}$ \\
современных тектонических движений, выражаемая
\end{tabular}

Средняя достоверность

Максимальная скорость

Дисперсия кинематики

Концентрация деформаций

Дисперсия кинематики

Совместимость кинематики

Структурная однородность

Преобладающая кинематика

Соотношение компонент

Ориентация сместителей

Ориентация сжатия

Ориентация сместителей

Преобладающая кинематика

Средняя достоверность Вертикальная скорость

Кинематическая ситуация

Ориентация напряжений

Стабильность развития распределением активных разломов

Приуроченность всех смещений к какому-либо главному магистральному разлому или активной разломной зоне

Единство, целостность системы разломов, которая снижается при наложения разных структурных планов и близости границ разных тектонических блоков

Структурно-кинематическое состояние, тип и целостность системы взаимосвязанных структурных элементов

Напряженно-деформированное состояние, направления осей тектонических напряжений и деформаций, проявлением которых стали активные разломы, представленные в БД
Соотношение между системами активных разломов разной достоверности, отражающее тенденции развития тектогенеза на позднекайнозойском этапе качестве независимых друг от друга разных предметов оценки. Каждая группа объектов БД, входящая в тот или иной участок, обрабатывается отдельно. Для каждого участка вычисляются одни и те же расчетные параметры, и после их геологической интерпретации сравниваются обобщенные целевые характеристики участков. Второй способ это общая обработка обширной разнородной территории, построение карты поля распределения расчетного параметра и ее интерпретация как единого целостного предмета анализа. В этом случае один алгоритм применяется последовательно для смежных прямоугольных участков, образующих ячейки общей матрицы. Такие действия обеспечивают построение полей расчетных параметров, затем анализ распределения и конфигурации аномалий параметров и на этой основе - районирование изучаемой территории по целевым характеристикам.

3. Сравниваемыми тестовыми участками могут быть отдельные разломные зоны (например, Дарваз-Алайская, Северо-Анатолийская) или целые геотектонические регионы, границы которых проведены по определенным структурным или геодинамическим критериям (например, Кавказский, Памирский). Можно сравнивать прямоугольные участки, в которые вписываются сравниваемые регионы или их наиболее характерные и представительные части. В этом случае тектонические гра- ницы не учитываются, но одинаковая площадь участков помогает корректно учитывать общее число (плотность) разломов и уровень активности территории. Принципы выбора участков для сравнения - их расположения, размеров и формы - зависят от конкретных задач, которые ставит перед собой исследователь. При построении полей расчетных параметров возможна либо детальная обработка отдельных областей для оценки соотношений ключевых разломов (например, Северо- и Восточно-Анатолийского сдвигов), либо обработка обширной территории (например, всего Альпийско-Гималайского пояса) для изучения общих закономерностей активной тектоники.

Последовательная реализация действий, описанных выше, требует решения трех задач. Первая задача состоит в подборе расчетных параметров, наиболее информативных для сравнения между собой разных участков изучаемой территории или ее районирования по целевым характеристикам. Используемые атрибуты и алгоритмы обработки должны обеспечивать контрастную дифференциацию территории, а параметры - обоснованно и однозначно соотноситься с целевыми характеристиками, адекватно отражать реальные геологические свойства изучаемой территории. Активная разломная тектоника показывает направление и скорость движения блоков - отражает режим деформирования земной коры. Требуется определить па- 
раметры, точно характеризующие этот режим. Интерпретация этих данных позволяет выяснить механизм тектогенеза.

Второй задачей является разработка способов интерпретации параметров для получения нового знания путем обработки самой БД, без привлечения априорных тектонических моделей и предварительных экспертных оценок. Существующие концепции должны сопоставляться с результатом уже проведенной интерпретации результатов обработки БД. Выбор участков для сравнения может опираться на личные представления авторов, но сама обработка производится по заранее разработанным, единообразным алгоритмам и не является интерактивной процедурой. Результаты должны давать сведения, которые невозможно получить при визуальном анализе карты разломов, представлять материал, по-новому отражающий проявления активной тектоники. Общий характер ориентировки, плотности, скорости разломов виден при их изображении на карте, но вычисление точных величин параметров позволяет численно сравнивать внешне похожие области, выявлять их различия, незаметные на карте, новую информацию для дальнейшего изучения.

Третьей задачей является разработка графических приемов демонстрации уже известных особенностей тектонического строения, позволяющей провести их интерпретацию на качественно новом уровне, выявить дополнительные аспекты. Результаты обработки БД должны быть представлены в наглядной и понятной форме - в виде карт распределения маркеров или различных диаграмм, совмещения маркерного и цветового отображения разных параметров. Информативным способом представления структурно-кинематической ситуации и характера напряженного состояния является построение роза-диаграмм разломов разной кинематики - форма представления статистически значимых структурно-кинематических соотношений. Второй способ - построение карт, которые посредством сеток условных символов-знаков, штриховых маркеров отображают, например, ориентировку осей деформаций. Третий способ - создание растровых карт, на которых разными цветами и яркостью были бы четко выражены максимумы и минимумы распределения параметров и изолиниями была бы подчеркнута изменчивость и конфигурация этих аномалий.

Возможности тектонического и геодинамического использования результатов обработки БД продемонстрированы на нескольких примерах, представляющих разные подходы к выбору изучаемой территории, разные способы обработки, вычисляемые параметры, варианты их визуализации и интерпретации.

\section{3. ПРИМЕРЫ ОБРАБОТКИ БД ДЛЯ ТЕКТОНИЧЕСКОГО И ГЕОДИНАМИЧЕСКОГО АНАЛИЗА}

При выборе районов, в отношении которых проводились обработка и сравнение, мы исходили из общепринятого неотектонического разделения Альпийско-Гималайского подвижного пояса. Cогласно этому разделению, центральная часть пояса включает два мегасегмента, отражающих давление со стороны Аравийского и Индостанского инденторов. При существенных различиях в строении и развитии областей, одинаково расположенных относительно инденторов, сходными чертами мегасегментов являются их асимметрия и роль инденторов в межплитном взаимодействии, фронтальные складчато-надвиговые зоны и крупные фланговые сдвиги, клинья латерального выжимания с признаками продольного растяжения, фронтальные и фланговые зоны предгорной складчатости, области удаленного воздействия инденторов. Таким образом, в каждом мегасегменте обособляются три тектонические провинции, отвечающие западному флангу, фронтальному сектору и восточному флангу синтаксисов (в Аравийском сегменте - Анатолийская, Кавказская и Иранская провинции, в Индостанском - Афганская, Памирская и Тибетская). В свою очередь, в каждой провинции с долей условности можно выделить области, разделенные между собой главными разломными зонами (рис. 2). Во фланговых провинциях выделяются северные области, отвечающие клину латерального выжимания между сдвигами - Левантским и Северо-Анатолийским, Загроса и Эльбурса, Чаманским и Герирудским, Каракорумским и Алтынтагским (это области A2, A7, И2, И7 на рис. 2), и южные области сопряженных с главным сдвигом предгорных складчатых зон - Западного Битлиса, Внешнего Загроса, Сулеймановых гор, отчасти Западных Гималаев (A1, А6, И1, И6). Во фронтальных провинциях обособляется южная область предгорной складчатости, например южнее Битлиса (A3), центральная область интенсивного тектогенеза - Малый Кавказ, Памир (A4, И4) и северная область деформаций края Евразийской плиты - Большой Кавказ, Тянь-Шань (A5, И5). В итоге, в каждом мегасегменте выделены семь областей, закономерно расположенных по отношению к границам соответствующих инденторов.

Выбранные примеры использования БД различаются размерами рассматриваемой территории (область, регион мегасегмента, центральная часть пояса), способом обработки данных (сравнительный, картографический), получаемыми расчетными параметрами (структурно-кинематические, тектонофизические), способами изображения (диаграммы, знаки движения, количественный фон) и 
интерпретации расчетных параметров для оценки изучаемых целевых характеристик.

Входные данные для всех предлагаемых способов обработки - содержащиеся в БД геометрические данные, т.е. координаты узлов линий разломов, и атрибутивные данные о разломах: преобладающий кинематический тип SNS1, второстепенный кинематический тип SNS2, ранг скорости RATE, ранг достоверности CONF. Получение расчетных параметров может быть автоматизировано в любом ГИС-пакете и включает несколько этапов обработку геометрии разломов (разбиение линии разлома на элементарные отрезки, определение длины, азимута простирания и координат центра каждого отрезка), интерпретацию атрибутов кинематики, учет атрибутов скорости и достоверности, расчет искомого параметра для элементарных отрезков разломов, осреднение в пределах тестового участка или ячейки матрицы.

Для всех предложенных примеров принципиальным является разложение атрибута скорости движения по разлому на главные кинематические компоненты - сбросовую, взбросовую и сдвиговую. В БД кинематика описывается двумя атрибутами SNS1 и SNS2. Если SNS2 не содержит значений, то скорость соответствует SNS1. Если же оба поля содержат значения, то атрибут скорости можно представить вектором на плоскости разлома суммой векторов главных кинематических типов (рис. 3). На иллюстрации показано, что середина сектора, соответствующего разлому смешанной кинематики, отстоит от ближайшего направления главной кинематики на $30^{\circ}$, т.е. вектор скорости раскладывается по направлениям главного и второстепенного кинематических типов в соотношении $\cos 30^{\circ} \approx 0.85$ и $\sin 30^{\circ}=0.5$ соответственно. Поскольку для обобщения и картографического представления необходимо оперировать горизонтальной проекцией перемещения по разлому, а для большинства разломов угол падения сместителя не был установлен, требуется принять средние величины углов падения для разных типов разломов. В качестве таковых нами приняты величины, отвечающие интервалам значений, характерным для всего мира: для сбросов - угол 60 [Jackson, 1987], для взбросов и надвигов $-60^{\circ}$ и $15^{\circ}$ соответственно.

\section{1. СРАВНИТЕЛЬНЫЙ СТРУКТУРНО-КИНЕМАТИЧЕСКИЙ АНАЛИЗ}

Рассчитана ориентация азимутов простирания разломов разной кинематики в отдельных областях. Для демонстрации результатов вычисления данного расчетного параметра (и сравнения по нему разных участков) наилучшим образом подхо- дит построение роза-диаграмм. Второстепенная компонента смещения учитывалась путем разложения вектора скорости на основные кинематические типы. Атрибуты основного типа кинематики группируются, а их простирание представляется на единой роза-диаграмме. Для этого в ГИС последовательно выполнены следующие процедуры:

1) обработка геометрии разломов;

2) интерпретация атрибутов кинематики: разложение вектора скорости на главные кинематические типы, вычисление горизонтальной проекции скорости, расчет веса отрезка в зависимости от длины, горизонтальной скорости и достоверности разлома;

3) пространственная выборка отрезков разломов для региона. Передача связок кинематика азимут - вес во внешнее программное обеспечение для построения роза-диаграммы.

Доли разломов разного кинематического типа выражаются на диаграмме линиями разного цвета. Удаленность линий диаграммы от центра (длина лепестков диаграммы) отвечает условным весовым единицам, которые приняты зависящими от атрибутов длины L и горизонтальной проекции скорости V разлома, осуществляется также учет его достоверности CONF (наиболее достоверные имеют вес $\mathrm{C}=1$, наименее - $\mathrm{C}=0.25)$, тогда применима формула: $\mathrm{p}=\mathrm{L} \cdot \mathrm{V} \cdot \mathrm{C}$. Расчет соответствующих статистик и графическое представление роза-диаграммы не входят в стандартные поставки ГИС-пакетов, но могут быть реализованы отдельно или в виде модуля ГИС [Kociánová, Melichar, 2016]. Описанный алгоритм был реализован авторами в ГИС-пакете ArcGIS и в виде отдельной программы для тектонических областей Альпийско-Гималайского подвижного пояса.

Построенные в результате роза-диаграммы являются расчетными параметрами, иллюстрирующими ориентацию азимутов простирания разломов разной кинематики в разных областях подвижного пояса (рис. 4). Это позволяет сравнивать выраженность систем разломов с разным типом движений, выявлять наиболее характерные простирания и вариативность этих систем, сравнивать режим деформирования разных тектонических регионов. Например, хорошо заметен разворот основных систем разломов во фланговых областях каждого из мегасегментов пояса относительно систем того же типа в его центральных областях. Отчетливо выражено преобладание разломов сдвиговой кинематики в клиньях латерального выжимания обоих мегасегментов, а также присутствие (особенно на западе) раздвиговой составляющей. Большинство южных областей предгорной складчатости, как и северные области удаленных деформаций, характеризуются преимущественно надвиговой кинематикой разломов. 


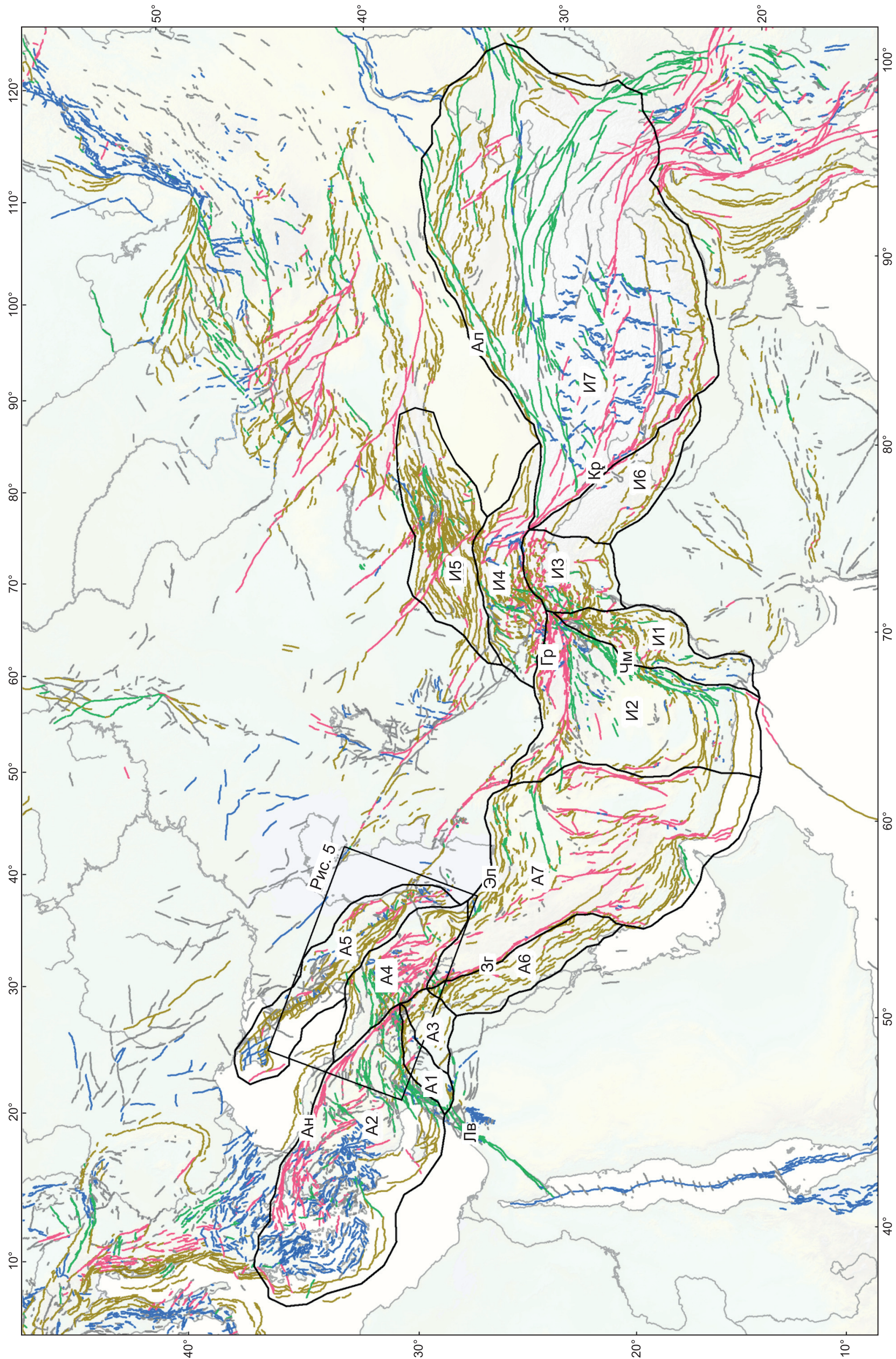


Рис. 2. Разделение центральной части Альпийско-Гималайского подвижного пояса на сегменты (буква А в индексе на карте - Аравийский сегмент, И - Индийский), провинции (цифры 1-2 в индексе - западно-фланговая провинция, 3-5 - осевая, 6-7 - восточно-фланговая) и области (1 и 6 - предгорной складчатости, 2 и 7 - латерального выжимания, 3 - фронтальной складчатости, 4 - осевых деформаций, 5 - удаленных деформаций). Одинаковые номера областей в пределах разных сегментов означают сходство их структурной позиции относительно тектонических инденторов - Аравийского и Индостанского выступов гондванских плит. Разломные зоны: Лв - Левант, Ан - СевероАнатолийская, Зг - Загросская, Эл - Эльбурская, Чм - Чаманская, Гр - Герирудская, Кр - Каракорумская, Ал - Алтынтагская. Кинематика разломов (главная компонента движения) показана цветом линий: красные - правые сдвиги, зеленые - левые сдвиги, желтые - взбросы и надвиги, синие - сбросы и раздвиги.

Fig. 2. The central part of the Alpine-Himalayan mobile belt divided into segments (letters in the index on the map: A - Arabian segment, $И$ - Indian segment), provinces (numbers 1-2 in the index - west-flank, 3-5 - axial, 6-7 - east-flank provinces) and areas ( 1 and 6 - piedmont folding, 2 and 7 - lateral squeezing, 3 - frontal folding, 4 - axial deformations, 5 - distant deformations). Similar numbers of regions within different segments indicate the similarity of their structural positions relative to tectonic indenters, the Arabian and Hindustan ledges of Gondwanian plates. Fault zones: Лв - Levant, Aн - North Anatolian, Зг - Zagros, Эл - Alborz, Чм - Chaman, Гр - Gerirud, Кр - Karakorum, Ал - Altyntag. Fault lines differ in colour to show fault kinematics (the main component of movement): red - right-lateral strike-slip, green - left-lateral strike-slip, yellow - reverse and thrust, blue - normal and extension faults.

Вместе с тем проявляются кинематические и, соответственно, геодинамические различия двух мегасегментов подвижного пояса. В западном Аравийском мегасегменте и на флангах, и в центре (см. рис. 2, области A2, A4, A7) лучше развиты системы правых сдвигов, а в восточном Индостанском мегасегменте (области И2, И4, И7) наблюдается противоположная ситуация с преобладанием разломов левосдвиговой кинематики. Аравийский мегасегмент отличается аномальным развитием на его западном фланге левых сдвигов в области предгорной складчатости (область A1), а также раздвигов в области клина латерального выжимания (область A2). Первое из этих отличий может быть обусловлено особым режимом развития Левантской трансформной зоны, а второе - влиянием Эллинской (a)

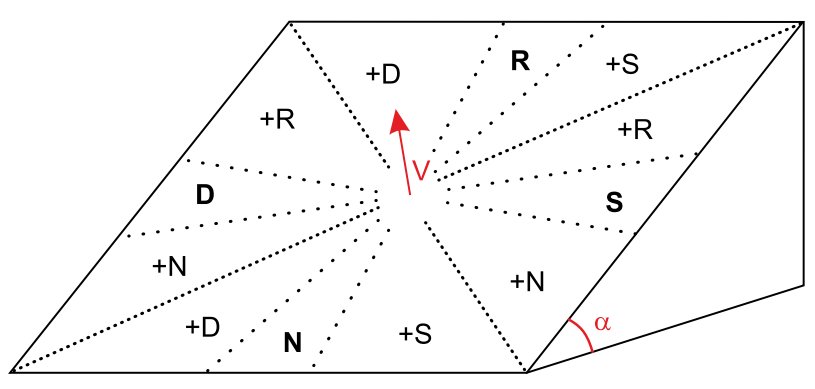

(б)

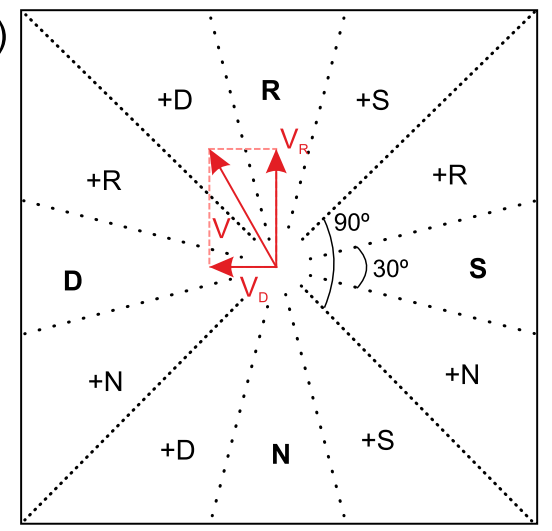

Рис. 3. Соответствие кинематического типа смещения (R - взброс, N - сброс, S - левый сдвиг, D - правый сдвиг; главная компонента - полужирное начертание, второстепенная компонента - знак «+» и нормальное начертание) направлению смещения по плоскости разлома с углом падения $\alpha$, в ортографической проекции (a) и на двумерной разломной плоскости (б). Взбросо-правосдвиговой кинематике (SNS1=“R”, SNS2=“D”) соответствует вектор V, который может быть представлен в виде суммы взбросового $\left(V_{R}\right)$ и правосдвигового $\left(V_{D}\right)$ смещения. Вектор сдвига лежит в горизонтальной плоскости; проекция взбросового вектора на горизонтальную плоскость определяется углом падения разлома $\alpha$.

Fig. 3. Correlation between the kinematic type of displacement ( R - reverse, $\mathrm{N}$ - normal, $\mathrm{S}$ - left-lateral strike-slip, $\mathrm{D}$ - rightlateral strike-slip faults; main component - bold letter, secondary component - sign "+" and letter) and the displacement direction along the fault plane with dip angle $\alpha$, in the orthographic projection $(a)$ and on the 2D fault plane (б). The reverse-right-lateral strikes-slip kinematics (SNS1="R", SNS2="D") corresponds to vector $V$, which can be represented as the sum of the reverse $\left(V_{R}\right)$ and right-lateral $\left(V_{D}\right)$ displacements. The strike-slip vector lies in the horizontal plane; the projection of the reverse vector on the horizontal plane is determined by dip angle $\alpha$. 


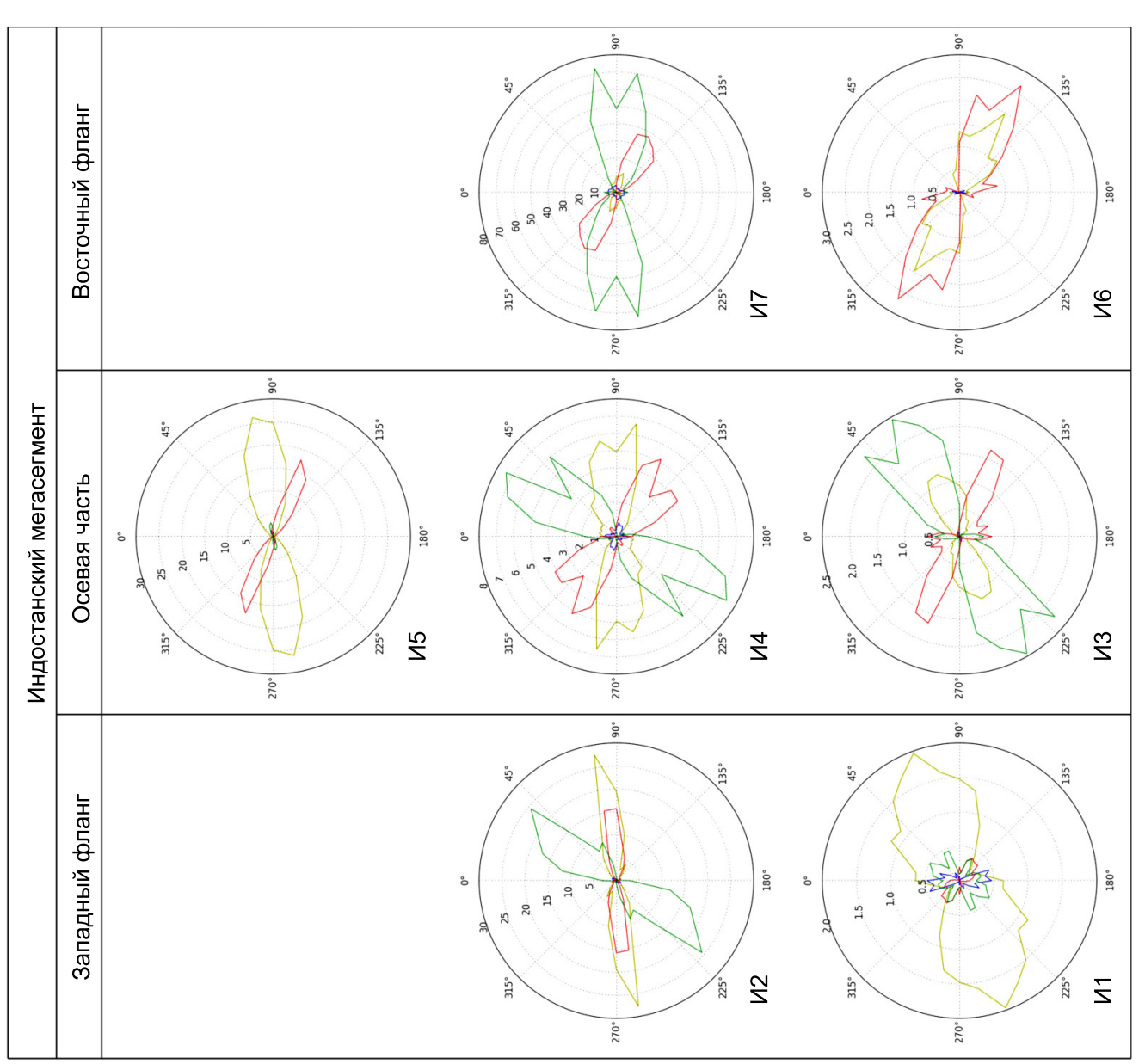

ส่

苟

ह

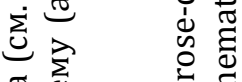

远造运

읍 咅穴

突记

苞氙

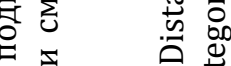

는

ชิ

卷 专

$\sum^{\pi} \frac{\pi}{10}$

㦴

焉造

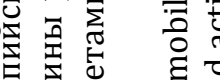

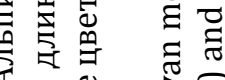

的密空

窎焉

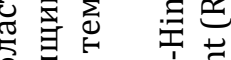

엉 $\overrightarrow{0}$ ฮ

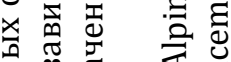

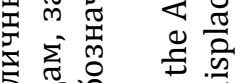

急寻皆

2.

可运范

$\sum \stackrel{0}{0}$

空焉

茜曹它

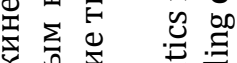

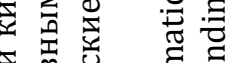

동 웅

गु 5 妾

党

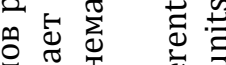

可志

氜

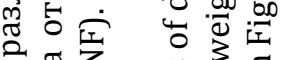

뭉월

牙记

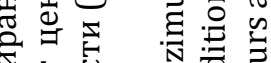

헝 중

完覀

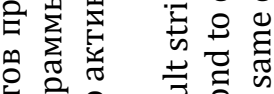

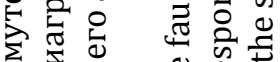

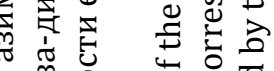

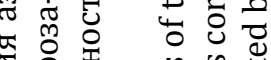

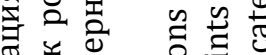

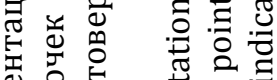

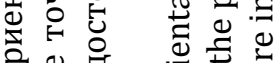

ठิ

+语舅

焉冠 
зоны субдукции. Индостанский мегасегмент отличается повсеместным распространением правых сдвигов во всех осевых областях с юга на север (области ИЗ, И4, И5).

В некоторых областях (например, области А2, A7, И4, И7 на рис. 2) отмечается характерный феномен расщепления единого лепестка роза-диаграммы, представляющего разломы определенного типа, на две части. Это отражает либо присутствие двух систем разломов близкой кинематики, но с разными долями главной и второстепенной компонент движений (не разделенных на диаграмме рассмотренного типа), либо изменение ориентировки разломов, отражающее процесс перестройки структурного плана. Об аналогичном явлении могут свидетельствовать и аномально широкие лепестки диаграммы (например, в области И1 на рис. 2), но это может быть следствием разнородности внутреннего строения тестового участка и требовать либо уточнения его границ, либо более дробного расчленения изучаемой территории.

\section{2. АНАЛИЗ ВЕКТОРНОГО ПОЛЯ ДЕФОРМАЦИЙ СОКРАЩЕНИЯ - УДЛИНЕНИЯ}

Помимо возможностей анализа кинематических типов нарушений обработка БД позволяет получать обобщенные характеристики систем разломов, тесно связанные с полем напряжений и дающие возможность оценить режим деформирования земной коры. При этом направление и величина деформаций могут быть показаны не только для региона в целом, но и непрерывным полем.

Поле деформаций характеризует течение материала земной коры. Направление движения масс без привлечения дополнительных материалов оценивать затруднительно, поскольку неизвестно, какое крыло пододвигается или надвигается. Результатом обработки БД соответственно становится ориентировка осей деформации без указания направления (их графическим представлением в этом случае будут штрихи, а не стрелки). Для упрощения визуального восприятия в этом случае вместо розадиаграмм уместно показывать главные оси сокращения и удлинения, характеризующие поле деформаций.

В качестве иллюстрации такого подхода обработаны материалы БД для фрагмента КавказскоАнатолийского региона, включающего Малый Кавказ (рис. 2, область А4). Для этого в ГИС выполнены процедуры:

1) обработка геометрии разломов;

2) интерпретация атрибутов кинематики: разделение вектора скорости на главные кинематические типы, вычисление величин удлинения или сокращения как произведения длины разлома и горизонтальной проекции соответствующей компоненты скорости;

3) определение направления удлинения или сокращения в зависимости от простирания и кинематики разлома;

4) расчет векторной суммы отдельно удлинения и сокращения в пределах скользящего окна - квадрата со стороной 100 км в равноплощадной картографической проекции. Шаг смещения окна равен его размеру (без перекрытия).

Использованные разложения вектора скорости на сокращение/удлинение для различных сочетаний главного (SNS1) и второстепенного (SNS2) типов кинематики в соответствии с рис. 3 приведены в таблице 3. Ориентация осей сокращения и удлинения земной коры показана на карте штрихами разного цвета. Величина штрихов пропорциональна десятичному логарифму величины сокращения - удлинения.

Карта векторов сокращения - удлинения (рис. 5), на которой показаны также границы областей, для которых рассчитаны роза-диаграммы ориентации разломов (см. рис. 2 и рис. 4), содержит важную геодинамическую информацию. Она иллюстрирует распределение преобладающих направлений главных осей деформаций и их соотношения, позволяет судить о преобладании сжатия либо растяжения, а также о преобладающих направлениях перемещения по активным разломам и их пространственной изменчивости.

На карте (рис. 5) хорошо видно, что для всей территории Кавказско-Анатолийского региона характерна северо-северо-восточная ориентировка осей сокращения. Очевидно резкое преобладание на всей рассмотренной территории процессов сокращения земной коры, в то время как отдельные участки с признаками удлинения имеют локальный и менее выраженный характер. Эти характеристики вполне соответствуют существующим представлениям о геодинамике региона и могут служить подтверждением корректности алгоритма расчета параметров.

Вместе с тем, полученное поле деформаций не является однородным: области различаются характером деформирования. Например, заметно изменение средней ориентировки осей сокращения с субмеридиональной на территории Малого Кавказа (см. рис. 2, область A4) до северо-северо-восточной на Большом Кавказе (см. рис. 2, область А5) и в предгорной зоне на юге (см. рис. 2, области A1, A3). В районе западного клина латерального выжимания (см. рис. 2, область А2) и вблизи Южного Каспия (см. рис. 2, восточная часть области A4) наблюдается хаотичная ориентация осей деформаций, здесь шире разброс их направлений, а величины деформаций весьма изменчивы. Заметно, что, по сравнению 
Т а б л и ц а 3. Разложение вектора скорости деформации на доли сокращения (вверху) и удлинения (внизу) и наиболее характерные углы падения $\alpha$ для разных сочетаний главного (атрибут SNS1) и второстепенного (SNS2) компонента кинематики

$\mathrm{T}$ a b l e 3. Decomposition of the strain rate vector into fractions of shortening (top) and lengthening (bottom) and the most characteristic dip angles $\alpha$ for different combinations of the main (SNS1) and secondary (SNS2) components of kinematics

\begin{tabular}{lllllllll}
\hline SNS1 $\backslash$ SNS2 & - & $\mathrm{D}$ & $\mathrm{S}$ & $\mathrm{T}$ & $\mathrm{R}$ & $\mathrm{N}$ & $\mathrm{E}$ & $\alpha$ \\
\hline $\mathrm{D}$ & $70 \%$ & - & - & $90 \%$ & $90 \%$ & $40 \%$ & $40 \%$ & $90^{\circ}\left(75^{\circ}\right)$ \\
& $70 \%$ & & & $40 \%$ & $40 \%$ & $90 \%$ & $90 \%$ & \\
$\mathrm{~S}$ & $70 \%$ & - & - & $90 \%$ & $90 \%$ & $40 \%$ & $40 \%$ & $90^{\circ}\left(75^{\circ}\right)$ \\
& $70 \%$ & & & $40 \%$ & $40 \%$ & $90 \%$ & $90 \%$ & \\
$\mathrm{~T}$ & $100 \%$ & $90 \%$ & $90 \%$ & - & $100 \%$ & - & - & $15^{\circ}$ \\
& $0 \%$ & $40 \%$ & $40 \%$ & & $0 \%$ & & & \\
$\mathrm{R}$ & $100 \%$ & $90 \%$ & $90 \%$ & $100 \%$ & - & - & - & $60^{\circ}$ \\
& $0 \%$ & $40 \%$ & $40 \%$ & $0 \%$ & & & & $60^{\circ}$ \\
$\mathrm{N}$ & $0 \%$ & $40 \%$ & $40 \%$ & - & - & - & - & \\
& $100 \%$ & $90 \%$ & $90 \%$ & & & & & \\
$\mathrm{E}$ & $0 \%$ & $40 \%$ & $40 \%$ & - & - & - & - & \\
\end{tabular}

с окружающими территориями, в пределах Малого Кавказа (см. рис. 2, область А4) больше локальных проявлений удлинения. Особенно выражены они в центральной части Малокавказской области, характеризующейся развитием плиоцен-четвертичного вулканизма. Деформации удлинения концентрируются также в районе сочленения восточной периклинали Большого Кавказа с Южно-Каспийской впадиной (см. рис. 2, восточная часть области A5), вдоль Восточно-Анатолийской и Северо-Анатолийской зон разломов, как и на других участках западного клина латерального выжимания (область А2).

\section{3. АНАЛИЗ РАСТРОВЫХ ПОЛЕЙ ДЕФОРМАЦИОННЫХ ХАРАКТЕРИСТИК}

Кроме векторного поля осей деформаций, обработка БД позволяет получать карты скалярных параметров, характеризующих деформационный процесс. Такие карты могут быть представлены в виде растровых (пиксельных) изображений произвольного разрешения и поэтому позволяют анализировать поле распределения параметра на обширных территориях, сохраняя высокую детальность.

На примере всей центральной части АльпийскоГималайского пояса выполнена обработка БД для определения характеристик тектонического течения верхнекоровых масс. Рассчитаны величины деформаций сокращения - удлинения и сдвиговых деформаций. В результате построены растровые карты деформационных полей, на которых участки, отвечающие преобладанию определенного типа деформаций, показаны пикселями разного цвета. Для этого в ГИС выполнены процедуры:
1) обработка геометрии разломов;

2) интерпретация атрибутов кинематики: выделение сбросовой/взбросовой компоненты вектора скорости, расчет ее горизонтальной проекции $V=V_{0} k \cos \alpha$;

3) умножение горизонтальной проекции скорости на длину отрезка и суммирование полученных значений внутри скользящего окна или тектонического района.

Данный алгоритм был реализован авторами скользящим окном размером 100 км, атрибуты были интерпретированы в соответствии с наиболее характерными в мировой практике значениями долей скорости сокращения - удлинения в общей скорости деформаций. Использованные доли скорости сокращения - удлинения $k$ в общей скорости деформации и наиболее характерные углы падения $\alpha$ для различных сочетаний главного (SNS1) и второстепенного (SNS2) типа кинематики показаны в таблице 4.

Количественной мерой, например, сокращения поперек разлома в конкретной точке служит горизонтальная проекция взбросовой компоненты скорости (скорость сокращения, мм/год), для разлома в целом - произведение скорости сокращения на длину разлома (уменьшение площади, $\mathbf{m}^{2} /$ год), для какой-либо территории (скользящего окна или тектонического региона), содержащей несколько разломов, - сумма уменьшения площади на каждом из разломов, приходящаяся на окно осреднения. Таким образом, значения параметра имеют размерность год ${ }^{-1}$ (доля площади за год) и отвечают величине сокращения - удлинения пикселя за счет всех разломных деформаций в его пределах. На 


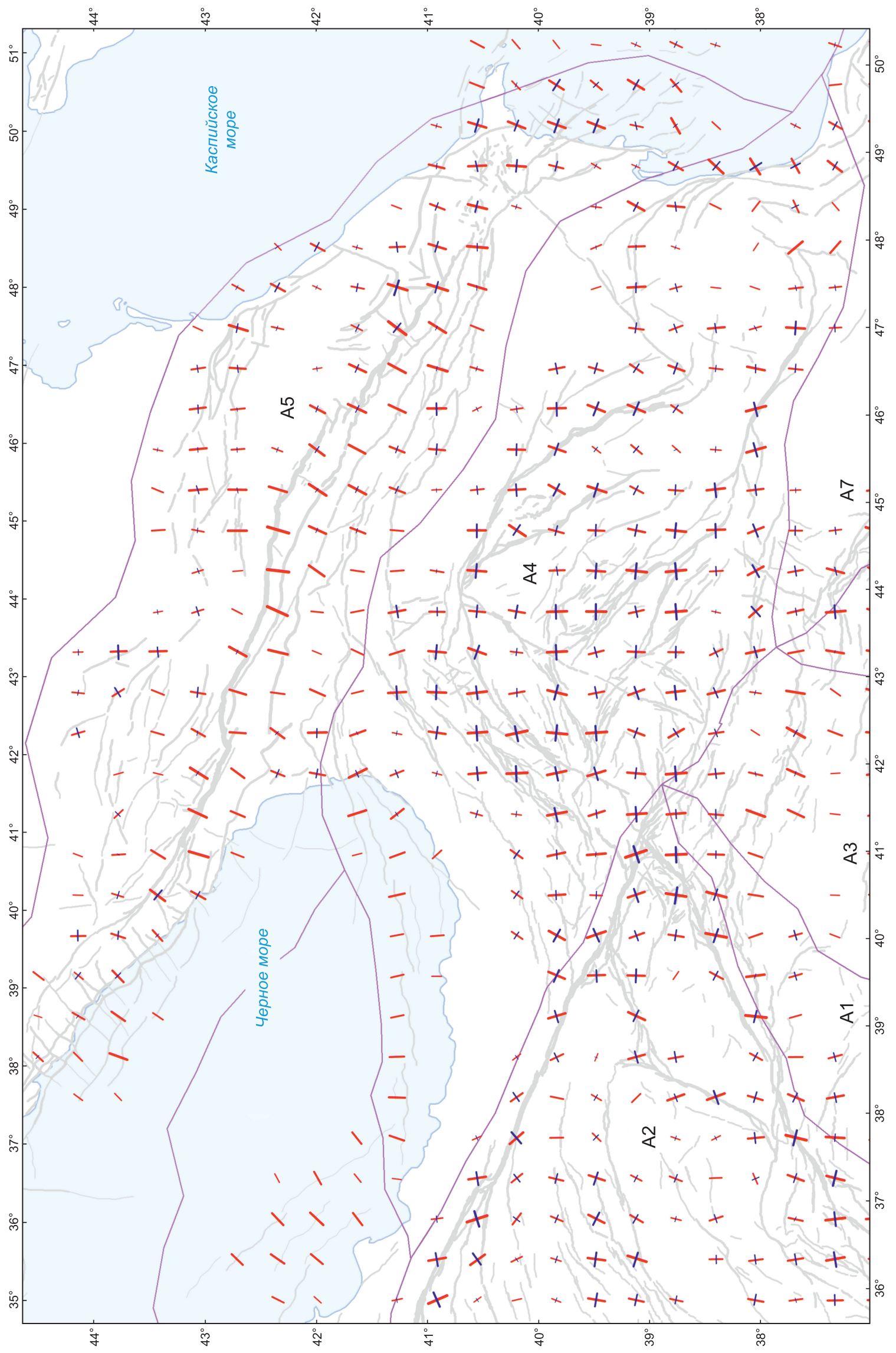


Т а б л и ц а 4. Доли скорости сжатия - растяжения $\boldsymbol{k}$ в общей скорости деформации и наиболее характерные углы падения $\alpha$ для разных сочетаний главного (атрибут SNS1) и второстепенного (SNS2) компонента кинематики

$\mathrm{T}$ a b l e 4. Fractions of compression/extension rate component $k$ in the total strain rate and the most characteristic dip angles $\alpha$ for different combinations of the main (SNS1) and secondary (SNS2) kinematic components

\begin{tabular}{lllllllll}
\hline SNS1 \SNS2 & - & $\mathrm{D}$ & $\mathrm{S}$ & $\mathrm{T}$ & $\mathrm{R}$ & $\mathrm{N}$ & $\mathrm{E}$ & $\alpha$ \\
\hline $\mathrm{D}$ & 0 & - & - & $50 \%$ & $50 \%$ & $50 \%$ & $50 \%$ & $90^{\circ}\left(75^{\circ}\right)$ \\
$\mathrm{S}$ & 0 & - & - & $50 \%$ & $50 \%$ & $50 \%$ & $50 \%$ & $90^{\circ}\left(75^{\circ}\right)$ \\
$\mathrm{T}$ & $100 \%$ & $85 \%$ & $85 \%$ & - & $100 \%$ & - & - & $15^{\circ}$ \\
$\mathrm{R}$ & $100 \%$ & $85 \%$ & $85 \%$ & $100 \%$ & - & - & - & $60^{\circ}$ \\
$\mathrm{N}$ & $100 \%$ & $85 \%$ & $85 \%$ & - & - & - & - & $60^{\circ}$ \\
$\mathrm{E}$ & $100 \%$ & $85 \%$ & $85 \%$ & - & - & - & - & $90^{\circ}$ \\
\hline
\end{tabular}

растровой карте участки (пиксели), характеризующиеся преобладанием сокращения или удлинения, показаны разным цветом, яркость которого пропорциональна абсолютной величине деформации.

Полученная карта центральной части Альпийско-Гималайского пояса отражает зоны концентрации сокращения или удлинения и особенности их проявления в разных тектонических областях (рис. 6). Для большей части рассматриваемой территории характерно сокращение земной коры, которое концентрируется преимущественно в осевых областях мегасегментов пояса (Кавказский, Памиро-Тянь-Шаньский регионы), на восточных флангах инденторов (Загрос, Гималаи), а также, отчасти, в Алтае-Саянской области внутриплитной активизации. Деформации удлинения проявлены в пределах главных клиньев латерального выжимания на внешних флангах подвижного пояса - в Анатолийско-Эгейском и Тибетско-Индокитайском регионах (см. рис. 2, области А2 и И7) и в Байкальской зоне внутриплитного рифтогенеза.

Рассчитаны также величины сдвиговых деформаций Альпийско-Гималайского пояса. Поскольку для расчета деформаций сокращения - удлинения вектор скорости раскладывается на сдвиговую и несдвиговую компоненты, построение поля сдвиговых деформаций во многом повторяет рассмотренный выше алгоритм. Проведя аналогичную последовательность операций, получаем меру преобладания правосдвиговых или левосдвиговых деформаций, имеющую размерность год-1 (доля площади за год). Полученные значения затем могут быть пересчитаны в угловые величины скашивания или чистого сдвига территории (скользящего окна или тектонического района) с размерностью рад/год. В этом случае к этапам ГИС-обработки добавляется пересчет меры преобладания деформаций в угловую скорость скашивания:

1) обработка геометрии разломов;

2) интерпретация атрибутов кинематики: выде- ление сдвиговой компоненты вектора скорости (вектор сдвига всегда горизонтален);

3) умножение скорости на длину отрезка и суммирование полученных значений $V$ внутри скользящего окна или тектонического района шириной b;

4) пересчет суммарного сдвига в угловые единицы $\omega=\operatorname{arctg}(\Sigma V / 0.5 b) \approx \Sigma V / 0.5 b$.

Описанный алгоритм реализован скользящим окном размером 100 км, атрибуты интерпретированы в соответствии с наиболее характерными для всего мира значениями. Возможные доли сдвиговой компоненты скорости $k$ и наиболее характерные углы падения $\alpha^{\circ}$ для различных сочетаний главного (SNS1) и второстепенного (SNS2) типов кинематики показаны в таблице 5. Как и в предыдущем примере, на карте пиксели с преобладанием право- или левосдвиговых деформаций показаны разным цветом, яркость которого отражает скорость деформаций сдвига с размерностью рад/год.

Карта выявляет зоны концентрации сдвиговых деформаций и особенности их распределения внутри подвижного пояса (рис. 7). В целом, можно отметить преобладание правосдвиговых деформаций в западной части подвижного пояса и левых сдвигов в его восточной части, возможно, отражающее латеральное растекание материала в стороны от центральной части пояса. По абсолютной величине деформаций прежде всего выделяются левосдвиговые зоны на западных флангах обоих инденторов (Левантская и Чаманская), а также зоны северного ограничения главных клиньев выжимания (правосдвиговая Северо-Анатолийская и левосдвиговая Алтын-Тагская). Обращает на себя внимание отличие восточной части Алтае-Саянского региона (с преимущественно левосдвиговыми деформациями) от его западной части (с преобладанием правых сдвигов). На карте хорошо проявлен масштаб и трансрегиональный характер приуроченных к восточным флангам инденторов зон правосдвиговых 


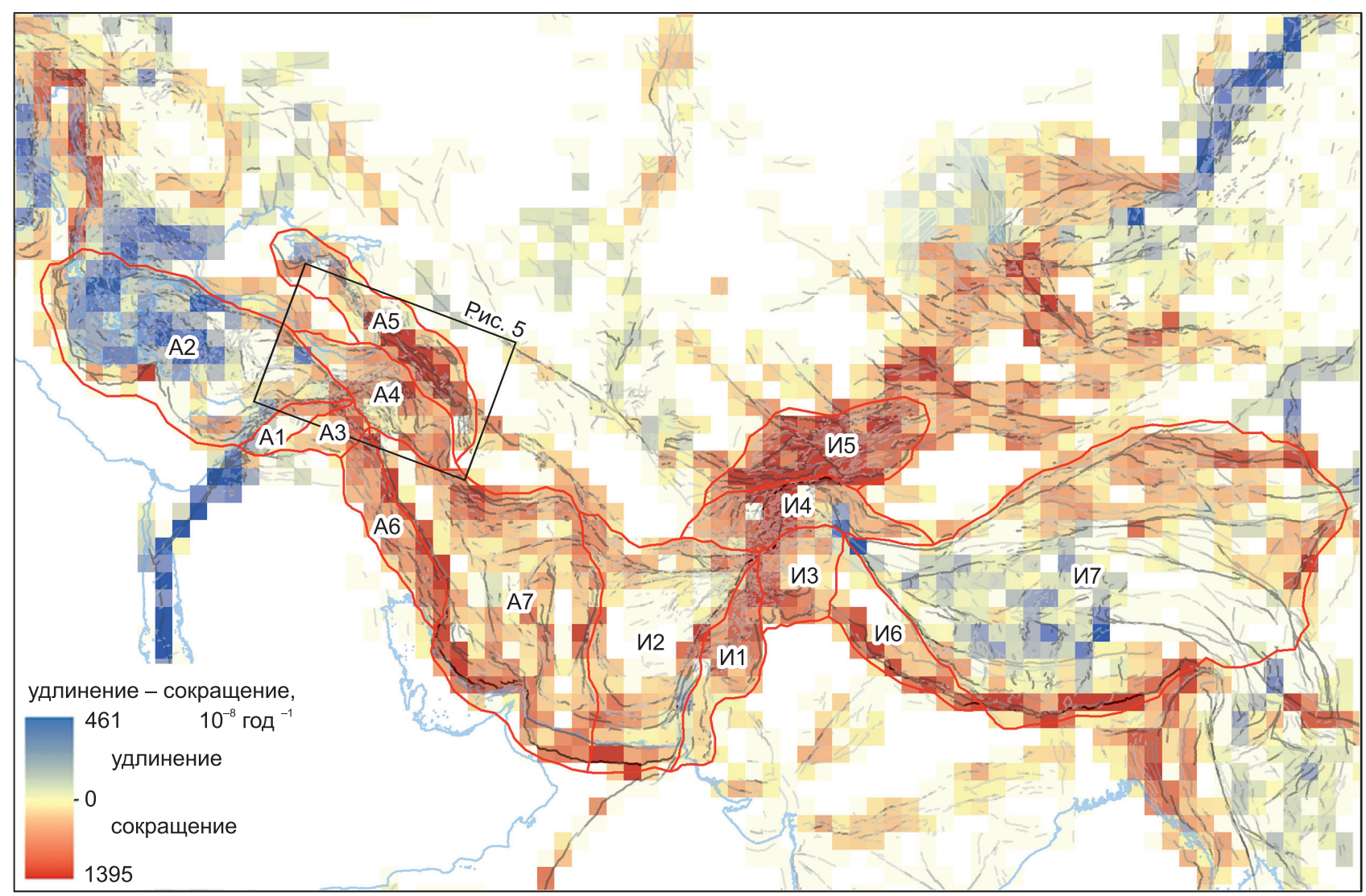

Рис. 6. Величины деформаций сокращения - удлинения Альпийско-Гималайского подвижного пояса, 10-8 год-1. Поле деформаций рассчитано скользящим окном размером 100 км. Преобладающее сокращение показано желтокрасными тонами, преобладающее удлинение - синими. Красными линиями показаны границы тектонических областей (см. рис. 2).

Fig. 6. Shortening/lengthening deformation values of the Alpine-Himalayan mobile belt, $10^{-8}$ year $^{-1}$. The deformation field is calculated using a sliding window $(100 \mathrm{~km})$. Yellow-red - dominant shortening; blue - dominant lengthening. Red lines boundaries of tectonic regions (see Fig. 2).

деформаций, объединяющих сдвиги Загроса и Северной Анатолии, а также Каракорумский и ТаласоФерганский сдвиги. Это может указывать на особую роль правых сдвигов в развитии региональных транспрессивных структур на позднекайнозойском этапе формирования подвижного пояса, а также его периферии. В частности, на карте отчетливо видна обширная внутриплитная область к северу от главных областей орогенеза, характеризуемая только правосдвиговыми деформациями. Совместный ана-

T а б л и ц а 5. Доли сдвиговой компоненты скорости $k$ в общей скорости деформации и наиболее характерные углы падения $\alpha$ для разных сочетаний главного (атрибут SNS1) и второстепенного (SNS2) компонента кинематики

$\mathrm{T}$ a b l e 5. Fractions of shear rate component $\boldsymbol{k}$ in the total strain rate and the most characteristic dip angles $\alpha$ for different combinations of the main (SNS1) and secondary (SNS2) kinematic components

\begin{tabular}{lllllllll}
\hline SNS1 \SNS2 & - & $\mathrm{D}$ & $\mathrm{S}$ & $\mathrm{T}$ & $\mathrm{R}$ & $\mathrm{N}$ & $\mathrm{E}$ & $\alpha$ \\
\hline $\mathrm{D}$ & $100 \%$ & - & - & $85 \%$ & $85 \%$ & $85 \%$ & $85 \%$ & $90^{\circ}\left(75^{\circ}\right)$ \\
$\mathrm{S}$ & $100 \%$ & - & - & $85 \%$ & $85 \%$ & $85 \%$ & $85 \%$ & $90^{\circ}\left(75^{\circ}\right)$ \\
$\mathrm{T}$ & 0 & $50 \%$ & $50 \%$ & - & 0 & - & - & $15^{\circ}$ \\
$\mathrm{R}$ & 0 & $50 \%$ & $50 \%$ & 0 & - & - & - & $60^{\circ}$ \\
N & 0 & $50 \%$ & $50 \%$ & - & - & - & - & $60^{\circ}$ \\
$\mathrm{E}$ & 0 & $50 \%$ & $50 \%$ & - & - & - & - \\
\hline
\end{tabular}




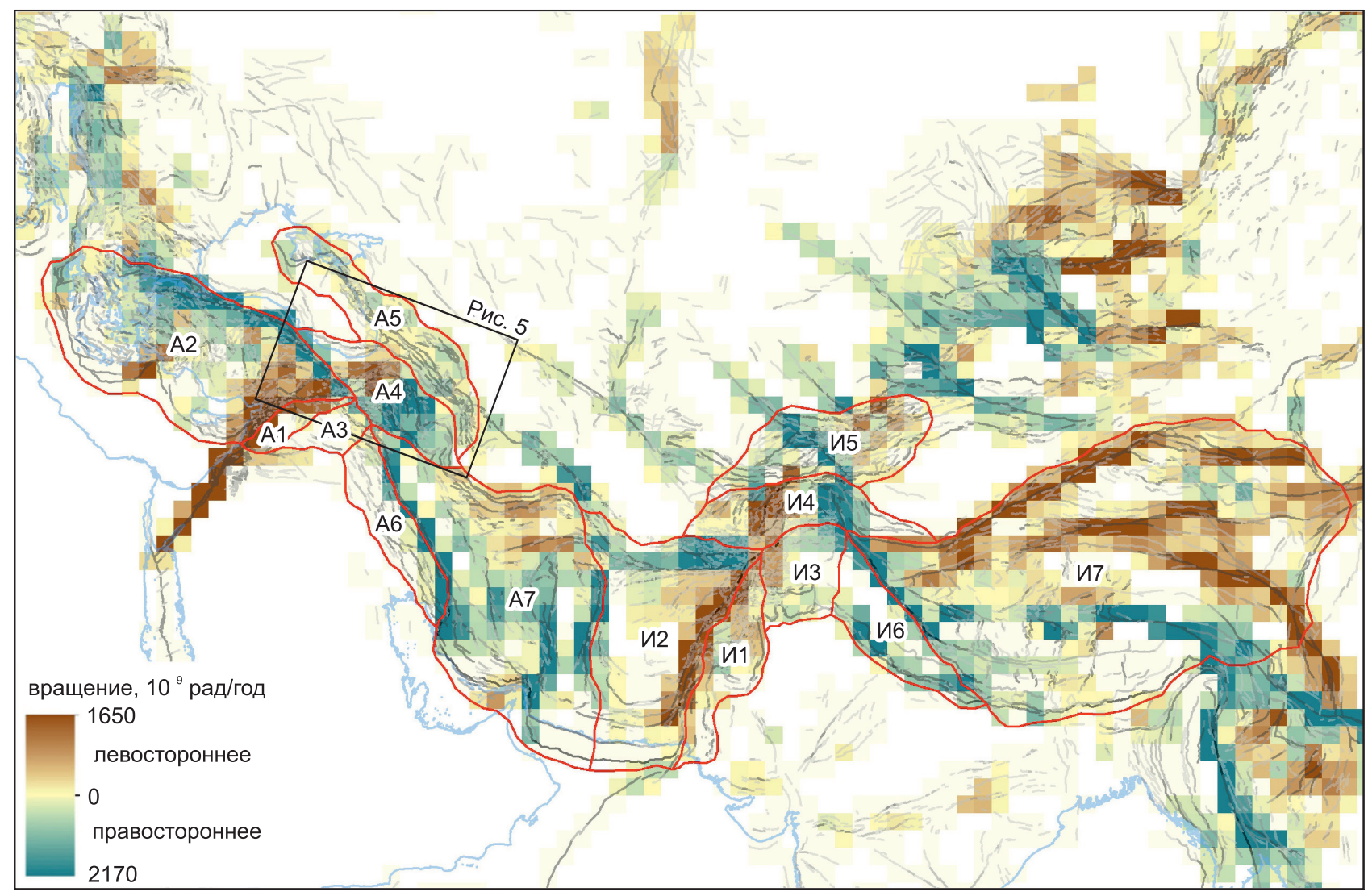

Рис. 7. Величины деформаций сдвига Альпийско-Гималайского подвижного пояса, 10-9 рад/год. Поле деформаций рассчитано скользящим окном размером 100 км. Преобладание правых сдвигов показано коричневыми тонами, левых сдвигов - зелеными. Красными линиями показаны границы тектонических областей (см. рис. 2).

Fig. 7. Shear deformation values of the Alpine-Himalayan mobile belt, $10^{-8} \mathrm{rad} / \mathrm{year}$. The deformation field is calculated using a sliding window $(100 \mathrm{~km})$. Brown - dominant right-lateral strike-slip faults; green - dominant left-lateral strike-slip faults. Red lines - boundaries of tectonic regions (see Fig. 2).

лиз карт сдвигов и сокращения - удлинения позволяет также судить о согласованности движений по разломным зонам разной кинематики.

\section{4. ПЕРСПЕКТИВЫ ОБРАБОТКИ БД}

Перспективными задачами при обработке БД являются углубление методических подходов к выделению тестовых участков и анализу данных и оценка возможностей использования дополнительных источников информации.

\section{1. УТОЧНЕНИЕ ГРАНИЦ ТЕСТОВЫХ УЧАСТКОВ}

Для решения конкретных тектонических задач требуется обоснованный выбор участков для обработки БД, отвечающих цели исследования, характеризующих предмет изучения максимально точно и полно. В данной работе уточнение активной кинематики отдельных областей Альпийско-Гималайского подвижного пояса основано на выделе- нии двух его мегасегментов, обусловленных давлением инденторов - Аравийского и Индийского выступов гондванских плит. При наличии принципиального сходства они различаются конфигурацией и размерами инденторов, типом, мощностью, возрастом и степенью однородности коры и литосферы, направлениями и скоростями движения плит, строением областей удаленного воздействия. Мегасегменты разделены на области, занимающие разное положение относительно инденторов - Аравийского и Индостанского выступов гондванских плит. Уточнить границы областей, выявить черты сходства и различия между областями, занимающими разное положение в структуре каждого мегасегмента и сходное положение в обоих мегасегментах, - задача дальнейших исследований. Отчасти материал для такого сравнения содержится в представленных результатах обработки БД, но более углубленный сравнительный анализ требует детализации масштаба исследования вплоть до сравнения отдельных зон разломов и участков концентрации деформаций. 
Перспективным может оказаться сравнительный анализ рассмотренных мегасегментов Альпийско-Гималайского пояса, особенно их субдукционной Крито-Эллинской части, с субдукционной Камчатской областью, Корякией, Курилами и прилегающей акваторией. Интересен для сравнения и Байкальский регион, представляющий обстановку континентального рифтогенеза в условиях транстензии, а также своеобразная система активных разломов Станового нагорья. Важной представляется оценка роли тектонической расслоенности литосферы в активном тектогенезе.

Возможно, в дальнейших исследованиях следует модернизировать сам принцип выделения тестовых участков (областей). При использованном способе их выделения возникает неопределенность в приуроченности к той или иной области крупных пограничных разломов с зонами их динамического влияния, например Главного сдвига в области Загроса или Чаманского сдвига в области Сулеймановых гор. Это затруднение можно устранить, если главные разломные зоны составят центральные части тестовых участков, а их границы будут проведены на максимальном удалении от зон наибольшей активности по осевым частям стабильных областей. Тогда результат обработки окажется статистически более достоверным, а принадлежность главных разломов - вполне определенной. Заметим, однако, что выделение областей и тестовых участков всегда отчасти условно, особенно если их границы проводить на удалении от главных разломных $30 н$.

\section{2. ГЕОДИНАМИЧЕСКИЕ АСПЕКТЫ УЧЕТА ДОСТОВЕРНОСТИ РАЗЛОМОВ}

Перспективным может стать углубленный анализ роза-диаграмм для более детальной характеристики структурно-кинематической ситуации. В рамках выполненного исследования для каждой области принимались в расчет все разломы, содержащиеся в БД, причем разломы, предположительно активные (категории достоверности CONF C и D), учитывались с меньшим весом, чем достоверные разломы категорий А и В. Это оправдано при изучении разломных движений позднеплейстоцен-голоценового возраста, поскольку нивелирует фактор недостаточно надежных и, возможно, даже ошибочных сведений, содержащихся в БД. Однако, согласно методике составления БД [Bachmanov et al., 2017], в качестве предположительно активных разломов с достоверностью С и D нередко выделялись нарушения с выразительными проявлениями подвижек плиоцен-раннечетвертичного возраста, но ненадежными и фрагментарно выраженными признаками позднечетвертичной активности (в отличие от достоверных категорий А и В, где наиболее выразительны проявления именно позднечетвертичных движений). В связи с этим в тех областях, где преобладают предположительно активные разломы (C-D), роза-диаграммы характеризуют в большей степени плиоцен-раннечетвертичную, чем позднечетвертичную, активность. Вследствие этого возникает перспектива сопоставления и выявления изменений полей напряжений от плиоцен-раннечетвертичной или раннечетвертичной стадии развития разломов к позднечетвертичной стадии путем сравнения роза-диаграмм активных разломов разной достоверности для одних и тех же провинций и тестовых участков.

Для отдельных областей мы построили розадиаграммы для активных разломов разных категорий достоверности. Обнаружились их структурнокинематические различия (рис. 8). Например, на юго-западном фланге Аравийского мегасегмента пояса (рис. 8, область A1) достоверные разломы представлены левыми сдвигами, а предполагаемые - правыми сдвиго-взбросами. Это может интерпретироваться как миграция активности в четвертичное время от предгорной Битлисской зоны в зону Левантского сдвига. Подобные перераспределения активности между системами разломов разных кинематических типов наблюдаются в областях A4, И3, И4 (рис. 8). Еще один пример - разворот против часовой стрелки и резкое преобладание левосдвиговых движений для системы достоверных разломов в западном клине выжимания (рис. 8, область И2) Индостанского мегасегмента. Это может быть связано с перераспределением активности от субмеридиональной Гиндукушской зоны к зоне Чаманского сдвига северо-северо-восточного простирания, что увязывается с существенно более высоким уровнем исторической сейсмичности последней. Подобные изменения ориентировки систем однотипных разломов отмечаются также в областях A7 и И4. Выявленные различия могут указывать на изменение структурно-кинематического типа и, соответственно, геодинамической обстановки разломообразования в течение плиоцен-четвертичного этапа.

Анализ роза-диаграмм поднимает вопросы методического характера. В целом, для большинства областей диаграммы показывают преобладание взбросовой кинематики (см. рис. 3). Но среди разломов с высокой достоверностью активности в БД предположительно содержится больше сдвигов, чем разломов других типов. Это может быть обусловлено свойствами земной коры либо недостатками методов изучения активных разломов (сдвиги легче выделяются, и лучше изучены характеристики движения по ним). Данный фактор следует учитывать при интерпретации результатов 

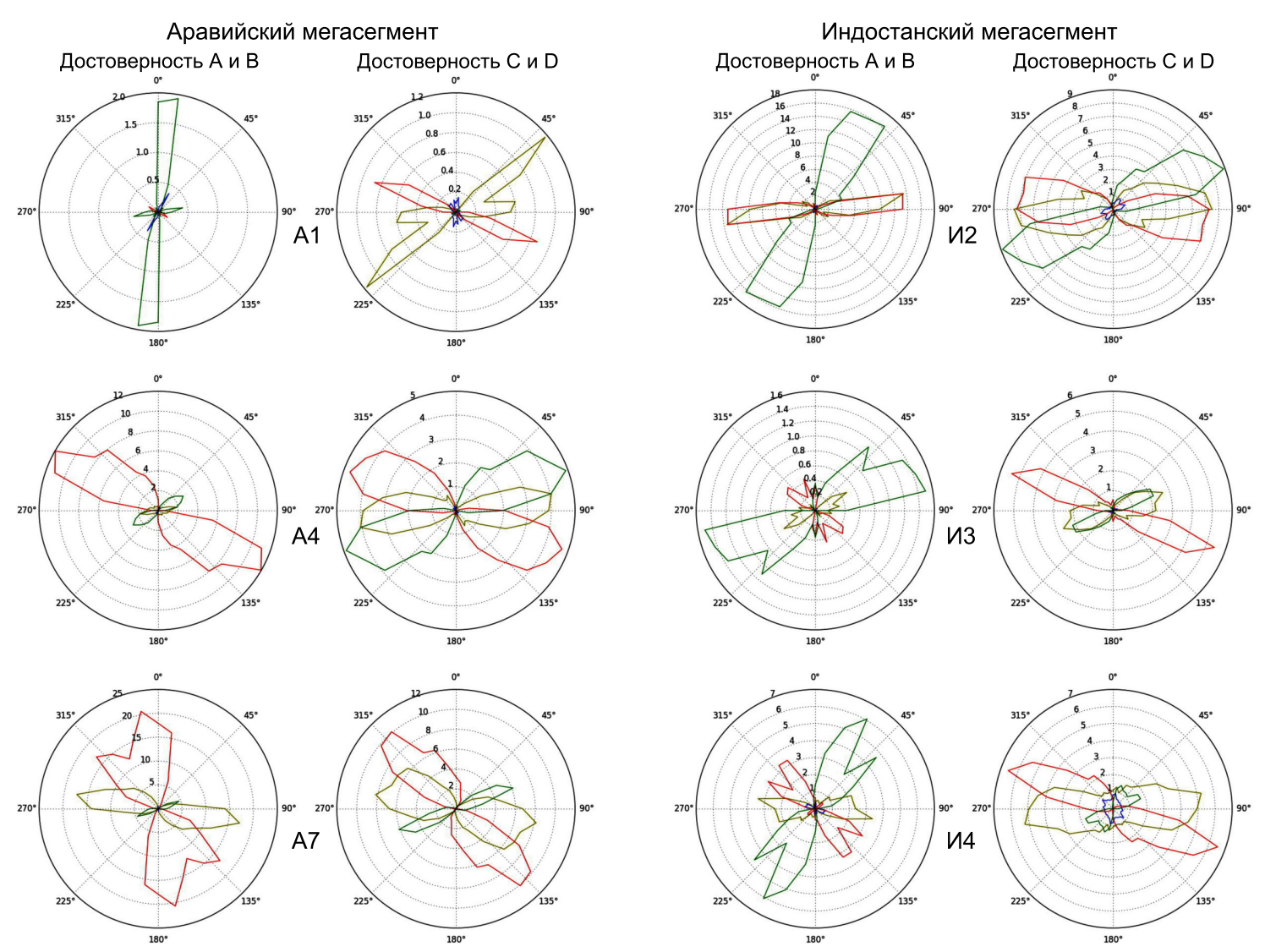

Рис. 8. Сравнение роза-диаграмм для разломов с разной достоверностью для некоторых областей АльпийскоГималайского подвижного пояса (см. рис. 2). Слева в каждой паре - диаграмма для разломов категорий достоверности А и В (с достоверными признаками позднечетвертичных движений), справа - для разломов категорий C и D (предположительно активные с достоверными плиоцен-четвертичными подвижками). Кинематические типы разломов обозначены теми же цветами, что на рис. 2.

Fig. 8. Comparison of the rose-diagrams for faults with different confidence categories for some regions of the AlpineHimalayan mobile belt (see Fig. 2). On the left in each pair - diagram for faults of confidence categories A and B (with reliable indicators of late Quaternary movements), on the right - diagram for faults of confidence categories C and D (supposedly active with reliably confirmed Pliocene-Quaternary movements). Kinematic types of faults are indicated by the same colours as in Fig. 2.

обработки БД. При этом сдвиги могут рассматриваться как особая форма проявления процесса сжатия и растяжения земной коры (точнее, сокращения и удлинения рассматриваемого участка территории) через реализацию механизмов транстензии и транспрессии.

\section{3. ПРИВЛЕЧЕНИЕ ИНСТРУМЕНТАЛЬНЫХ ДАННЫХ}

Перспективным направлением исследований представляется обработка БД совместно с инструментальными данными, например цифровыми моделями рельефа или мировыми каталогами землетрясений. Эти материалы ценны при автоматизированной обработке, поскольку, как и сама БД, они созданы по единым для всей изучаемой территории методикам (технологиям) и представлены в строгом цифровом формате. Возможно также при- влечение других геофизических данных, например карт изостатических аномалий и их производных (градиентов изостазии), теплового потока, и геохимических индикаторов активной тектоники. Эти материалы отчасти уже включены в БД и учтены при обосновании атрибутов и уточнении конфигурации разломов. Вместе с тем при составлении БД учитывались лишь отдельные, наиболее выраженные проявления и аномалии параметров, представленных на этих материалах. Преобладающая их часть не нашла конкретного отражения в БД, хотя имеет отношение к отраженным в ней проявлениям активной тектоники.

Необходимо разработать алгоритмы, позволяющие в полном объеме учитывать такие материалы при обработке БД путем включения всех рассмотренных выше цифровых данных непосредственно в алгоритм расчета тех или иных парамет- 
ров, вместо того чтобы проводить их экспертное сопоставление уже на этапе интерпретации полученного результата. В случае использования в обработке цифровой модели рельефа наибольшее значение имеют угол и направление наклона поверхности, градиент поверхности рельефа, амплитуда уступа между выровненными участками территории, рассчитанные вдоль линий соответствующих разломов.

Привлечение данных о рельефе и сейсмичности не означает изменения критериев выделения и параметризации активных разломов, но позволит оценить корреляцию между кинематическими типами разломов и вертикальной компонентой движения по ним и особенностями рельефа и сейсмической активности. Интерпретация этих расчетных параметров поможет косвенно оценить такую целевую характеристику, как стабильность развития - постоянство уровня и характера позднекайнозойских движений.

\section{5. ЗАКЛЮЧЕНИЕ}

Показано значение базы данных активных разломов для решения тектонических и геодинамических задач, продемонстрированы возможности автоматизированной компьютерной обработки этой информации. Выделены три этапа преобразования информации: оценка исходных данных для обработки, вычисление расчетных параметров и получение целевых характеристик изучаемой территории. Определены целевые характеристики и расчетные параметры, наиболее информативные для сравнения разных геотектонических областей, адекватно отражающие геологические свойства изучаемой территории. Выявлены комплексы атрибутов и алгоритмы обработки, обеспечивающие контрастную дифференциацию территории по расчетным параметрам. Это позволяет выявлять различия областей, незаметные при визуальном анализе карты разломов и требующие дальнейшего изучения, исследовать неожиданные аспекты в проявлениях активной тектоники, получать новые знания путем обработки БД.

Представлены примеры обработки БД, различающиеся размерами территории - центральной части Альпийско-Гималайского подвижного пояса и его отдельных областей. Построены роза-диаграммы разломов разной кинематики для сравнения структурно-кинематической обстановки тестовых участков, векторные карты деформационного поля, отображающие ориентировку осей сокращения и удлинения, растровые карты поля деформаций, на которых цветовой шкалой показаны аномалии их распределения. Новые формы демонстрации особенностей активной тектоники позволяют провести их интерпретацию на качественно новом уровне, например выявить продольное к поясу растяжение в пределах клиньев латерального выжимания на флангах инденторов или трансрегиональный характер приуроченных к восточным флангам инденторов зон правосдвиговых деформаций.

Рассмотрены перспективные направления дальнейших исследований на основе обработки БД. Выявлены проблемы выбора и определения границ областей, оптимальных для сравнительного анализа. Намечены возможности использования атрибута достоверности активности разломов для выявления признаков изменения структурного плана и перераспределения тектонической активности в течение плиоцен-четвертичного этапа развития. Рассмотрены перспективы компьютерной обработки БД совместно с независимыми, инструментальными, данными.

Предложенные в статье способы и варианты обработки не исчерпывают всех возможностей БД Приемы ее обработки могут быть расширены в соответствии с целями конкретных исследований и выполнены для любого входящего в БД региона. Полученные результаты важны для изучения активной тектоники и геодинамики регионов и могут представлять интерес для широкого круга исследователей в областях тектонофизики, сейсмотектоники, математического моделирования геологических процессов.

\section{6. БЛАГОДАРНОСТИ}

Работа выполнена за счет средств Российского научного фонда (проект № 17-17-01073). Часть исходных материалов собрана в рамках исследований по бюджетной теме № АAАА-А17-117030610107-3 Геологического института РАН.

\section{7. ЛИТЕРАTУРА / REFERENCES}

Active Faults Database, 2019. Geological Institute of the Russian Academy of Sciences. Laboratory of neotectonics and recent geodynamics (in Russian) [База данных активных разломов. Геологический институт РАН. Лаборатория неотектоники и современной геодинамики. 2019]. Available from: http://neotec.ginras.ru/database.html (last accessed April 14, 2019). 
Bachmanov D.M., Kozhurin A.I., Trifonov V.G., 2017. The Active Faults of Eurasia Database. Geodynamics \& Tectonophysics 8 (4), 711-736 (in Russian) [Бачманов Д.М., Кожурин А.И., Трифонов В.Г. База данных активных разломов Евразии // Геодинамика и тектонофизика. 2017. Т. 8. № 4. С. 711-736]. https://doi.org/10.5800/GT-2017-84-0314.

Basili R., Valensise G., Vannoli P., Burrato P., Fracassi U., Mariano S., Tiberti M.M., Boschi E., 2008. The Database of Individual Seismogenic Sources (DISS), version 3: summarizing 20 years of research on Italy's earthquake geology. Tectonophysics 453 (1-4), 20-43. https://doi.org/10.1016/j.tecto.2007.04.014.

Jackson J.A., 1987. Active normal faulting and crustal extension. In: M.P. Coward, J.F. Dewey, P.L. Hancock (Eds.), Continental extensional tectonics. Geological Society, London, Special Publications, vol. 28, p. 3-17. https://doi.org/ 10.1144/GSL.SP.1987.028.01.02.

Kociánová L., Melichar R., 2016. OATools: An ArcMap add-in for the orientation analysis of geological structures. Computers \& Geosciences 87, 67-75. https://doi.org/10.1016/j.cageo.2015.12.005.

Lunina O.V., 2016. The digital map of the Pliocene-Quaternary crustal faults in the southern East Siberia and the adjacent Northern Mongolia. Geodynamics \& Tectonophysics 7 (3), 407-434 (in Russian) [Лунина О.В. Цифровая карта разломов для плиоцен-четвертичного этапа развития земной коры юга Восточной Сибири и сопредельной территории Северной Монголии // Геодинамика и тектонофизика. 2016. Т. 7. № 3. С. 407-434]. https://doi.org/10.5800/GT-2016-7-3-0215.

Lunina O.V., Gladkov A.S., Sherstyankin P.P., 2010. A new electronic map of active faults for Southeastern Siberia. Doklady Earth Sciences 433 (2), 1016-1021. https://doi.org/10.1134/S1028334X10080064.

Styron R., Taylor M., Okoronkwo K., 2010. Database of active structures from the Indo-Asian collision. Eos, Transactions American Geophysical Union 91 (20), 181-182. https://doi.org/10.1029/2010E0200001.

Trifonov V.G., 1997. World map of active faults, their seismic and environmental effects. In: D. Giardini, S. Balassanian (Eds.), Historical and prehistorical earthquakes in the Caucasus. Kluwer Acad. Publ., Dordrecht, p. 169-180.

Trifonov V.G., 2004. Active faults in Eurasia: general remarks. Tectonophysics 380 (3-4), 123-130. https://doi.org/ 10.1016/j.tecto.2003.09.017.

Trifonov V.G., Soboleva O.V., Trifonov R.V., Vostrikov G.A., 2002. Recent Geodynamics of the Alpine-Himalayan Collision Belt. GEOS, Moscow, 225 p. (in Russian) [Трифонов В.Г., Соболева О.В., Трифонов Р.В., Востриков Г.А. Современная геодинамика Альпийско-Гималайского коллизионного пояса. М.: ГЕОС, 2002. 225 с.].

Ulomov V.I., Shumilina L.S., 1999. Set of General Seismic Zoning Maps of the Russian Federation - OSR-97. Scale 1:8000000. Explanatory Note and a List of Cities and Towns Located in Regions of Seismic Hazard. UIPE, Moscow, 57 p. (in Russian) [Уломов В.И., Шумилина Л.С. Комплект карт общего сейсмического районирования территории Российской Федерации - ОСР-97. Масштаб 1:8000000. Объяснительная записка и список городов и населенных пунктов, расположенных в сейсмоопасных районах. М.: ОИФЗ, 1999. 57 с.].

Woessner J., Laurentiu D., Giardini D., Crowley H., Cotton F., Grünthal G., Valensise G., Arvidsson R., Basili R., Demircioglu M.B., Hiemer S., 2015. The 2013 European seismic hazard model: key components and results. Bulletin of Earthquake Engineering 13 (12), 3553-3596. https://doi.org/10.1007/s10518-015-9795-1.

\section{Дмитрий Михайлович Бачманов}

канд. геол.-мин. наук, с.н.с.

Геологический институт РАН

119017, Москва, Пыжевский пер., 7, Россия

\e-mail:dmbv@mail.ru

(iD) https://orcid.org/0000-0001-7963-5719

Егор Александрович Зеленин

канд. геол.-мин. наук

Геологический институт РАН

119017, Москва, Пыжевский пер., 7, Россия

e-mail: egorzelenin@mail.ru

(iD) https://orcid.org/0000-0003-3733-1922

\section{Dmitry M. Bachmanov}

Candidate of Geology and Mineralogy, Senior Researcher

Geological Institute of RAS

7 Pyzhevsky lane, Moscow 119017, Russia

Egor A. Zelenin

Candidate of Geology and Mineralogy

Geological Institute of RAS

7 Pyzhevsky lane, Moscow 119017, Russia 


\section{Андрей Иванович Кожурин}

докт. геол.-мин. наук

Геологический институт РАН

119017, Москва, Пыжевский пер., 7, Россия

Институт вулканологии и сейсмологии ДВО РАН

683006, Петропавловск-Камчатский, бульвар Пийпа, 9, Россия

e-mail: anivko@yandex.ru

(iD) https://orcid.org/0000-0003-2741-3334

\section{Владимир Георгиевич Трифонов}

докт. геол.-мин. наук, профессор

Геологический институт РАН

119017, Москва, Пыжевский пер., 7, Россия

e-mail: trifonov@ginras.ru

(iD) https://orcid.org/0000-0003-3778-4710

\section{Andrei I. Kozhurin}

Doctor of Geology and Mineralogy

Geological Institute of RAS

7 Pyzhevsky lane, Moscow 119017, Russia

Institute of Volcanology and Seismology, Far East Branch of RAS

9 Piip Boulevard, Petropavlovsk-Kamchatsky 683006, Russia

\section{Vladimir G. Trifonov}

Doctor of Geology and Mineralogy, Professor

Geological Institute of RAS

7 Pyzhevsky lane, Moscow 119017, Russia 